\title{
Competition and the Strategic Choices of Churches*
}

\author{
Adam D. Rennhoff ${ }^{\dagger}$ \\ Middle Tennessee State University, Murfreesboro, TN \\ Mark F. Owens ${ }^{\ddagger}$ \\ Middle Tennessee State University, Murfreesboro, TN
}

\begin{abstract}
In this paper, we examine how the decisions of churches are impacted by the decisions of rival churches. Using a novel data set of Christian churches in two suburban Nashville, TN counties, we estimate a model of strategic interaction based on empirical models of discrete games. We focus on a church's decision of whether or not to provide a week-day child care program. Empirical evidence indicates that churches are more likely to offer a service when a nearby same-denomination church offers it, but are less likely to offer the service if a nearby different-denomination church offers the service. This suggests that churches may feel pressure to match the services offered by same-denomination churches. Using our estimates, we conduct counterfactual simulations which indicate that a new church's entry may increase or decrease the number of churches offering child care depending on the size and denomination of the entrant. Additional counterfactual simulations indicate that in some cases, increases in population may decrease the probability of a church offering child care.
\end{abstract}

Key words: nonprofits; churches; strategy; discrete games

JEL categories: L10; L30; Z12

\footnotetext{
* The authors would like to thank J. Laron Kirby for his invaluable research assistance. We would also like to thank seminar participants at the University of Georgia and the 2009 Southern Economic Association Conference.

† Adam D. Rennhoff, Assistant Professor, Department of Economics and Finance, Middle Tennessee State University, Murfreesboro, TN 37132, phone: 615-898-2931, fax: 615-898-5596, email: rennhoff@mtsu.edu ¥ Mark F. Owens, Assistant Professor, Department of Economics and Finance, Middle Tennessee State University, Murfreesboro, TN 37132, phone: 615-898-5617, fax: 615-898-5596, email:

mfowens@mtsu.edu
} 


\section{Introduction}

Religious congregations provide a wide variety of services to local communities. They provide aid for those in need, coordinate social activities, and provide child care along with many other service activities. The wide variety of services that churches offer has the ability to address community needs and benefit a large number of individuals. ${ }^{1}$ While the benefit of these services is difficult to quantify, prior studies find that religious involvement is correlated with greater life expectancy (McCullough et al., 2000) and higher incomes (Gruber, 2005). Though causality cannot be certain, this is at least suggestive that churches generate social benefits, which could be related to the services they provide. Access to many church-provided services is not limited strictly to church members, and the benefits extend to non-members in the community at-large particularly when churches address community needs not met by other organizations.

Given the large (and varied) roles that churches play in local communities, it is somewhat surprising how infrequently economists have studied the behaviors and choices of churches themselves. ${ }^{2}$ The relatively small amount of research on church behavior may be at least partially data driven, since many forms of charitable giving are informal and unobservable, making the benefits resulting from church-sponsored services difficult to quantify. In addition, churches may have different motivations and considerations in entering the market for services than do other organizations. It is often the case that local governments and

\footnotetext{
${ }^{1}$ We recognize that not all religious congregations refer to themselves as a "church." However, this is the common convention for our sample of Christian churches. We refer to religious congregations as "churches" for brevity.

${ }^{2}$ A recent EconLit keyword search for "church" yielded 310 results, while a keyword search for "airline" revealed 826 results in peer-reviewed journals.
} 
for-profit firms offer close substitutes for the services offered by churches. In these instances, it is unclear whether churches are providing a service to meet an unserved need in the community, or instead to match services with other churches in order to attract members. It is also common for several churches, either from the same or from different denominations, to work together in larger endeavours suggesting either gains from cooperation, or possibly competitive pressures to match others. Together these unique features make the decisions of a church to offer services an interesting area for economic research.

In this paper, we set out to formally model the behavior of Christian churches by examining the decision of whether or not to provide a service. ${ }^{3}$ We specify a model, based on empirical models of discrete games, that allows church payoffs to depend on the decisions of rival churches. ${ }^{4}$ The model incorporates unique features of church decisions by allowing the degree of interdependence between any two churches to depend on the denomination of each church and the distance between the churches' locations. In this regard, we seek to measure whether there is any evidence of strategic interaction between churches.

To conduct our study, we construct a unique data set of all Christian churches in two suburban Nashville, Tennessee counties. We collect a rich set of church characteristics using published works, online resources, and telephone calls. In addition we conduct physical inspections of each church and record numerous observable characteristics about the features of the church buildings and property. Together these sources allow us to compile a detailed set of characteristics for each church which is unavailable through other sources.

\footnotetext{
${ }^{3}$ The decision to focus on Christian churches, as opposed to including all types of religious congregations, is empirically-motivated. More on this will be discussed in Section 3.

${ }^{4}$ The term "rival" should not be read to imply hostility. We simply use the term to acknowledge that the desire to increase the congregation size is, to a large degree, a zero-sum game.
} 
Our primary set of results considers the decision to offer a child care program (either full-time or a "mother's day out" part-time day care program). We choose this decision for several reasons. First, church-sponsored child care plays a large role in the market and the benefits of the service extend well beyond the members of a church. A National Council of Churches (NCC) study in the early 1980s found that Christian churches were the singlelargest provider of child care services in the U.S. (Lindner, Mattis, and Rogers, 1983). The NCC study found that for every child in church on Sunday, there were eight children in the church-run child care center during the week. Second, the decision to offer child care is easier to observe and quantify than other services that churches may provide. Third, the choice to offer child care involves substantial time costs of planning, as well as explicit costs for labor, capital, and physical space making this decision a good candidate for the study of strategic interactions.

Our results support the basic hypothesis that a church's decisions are affected by the decisions of other churches. Interestingly, we find that a church's response to the decision of another nearby church to offer day care service depends crucially on the denomination of the rival. Same-denomination churches are strategic complements (upward-sloping reaction functions) meaning, holding all else constant, a church is more likely to provide child care if a nearby same-denomination church offers it. We interpret this finding as implying that churches compete with other churches of the same denomination for potential members and may feel compelled to match the services or amenities others offer. This result appears to be at odds with a possible hypothesis one might have that same-denomination churches cooperate in making denomination-optimal child care decisions. 
In contrast to the same-denomination results, we find that different-denomination churches are strategic substitutes (downward-sloping reaction functions) meaning that, holding all else constant, when a different denomination church offers child care it decreases the probability of a nearby church offering it as well. We interpret this finding as implying that when different-denomination churches provide care it shrinks the pool of potential children and reduces the need for the service in the community. The effects for both same and different denominations diminish as the geographic distance between churches increases. These finding are robust to alternative specifications of the value function which alter the relevant peer group of comparison for the churches by the size of the congregation. In addition, the same patterns emerge when the model is estimated using a subsample of only the Southern Baptist, Church of Christ, and Methodist denominations.

We use our estimates to conduct counterfactuals that simulate the likely impact of a new church's entry and of demographic changes in the area. Since the impact of an entrant depends on whether it is a same or different denomination church, there is no single conclusion regarding the impact of increased competition. Churches that share the same denomination as the entrant become more likely to offer child care and churches of different denominations become less likely to offer it. The net effect on the total number of existing churches offering child care is ambiguous. These findings indicate that increased competition, as measured by an increase in the number of churches, may (in some cases) reduce the number of child care programs.

We also find that the impact of increasing population and income for all churches by the same percentage change has different implications in different geographic areas within our 
sample. Some churches become more likely and some become less likely to offer child care as a result of the change. This result highlights the benefit of using the discrete game modeling approach, as a standard binary probit or logit would unambiguously predict an increase in the provision of child care as population or income increases.

As an anecdotal test of the reasonableness of our results, we also use our data to estimate the decision of a church to operate a website. We believe strategic interdependence is less likely for the website decision than for the day care decision because providing a website requires far less planning and lower costs. Consistent with our prior beliefs, we find notably weaker interdependence in the website decision.

The remainder of the paper is organized as follows. The next section contains a brief review of relevant research in the economic literature relating to churches and the empirical models of discrete games. The data used in this study are described in Section 3 and the empirical model and estimation approach are presented in Section 4. Estimates and counterfactual simulations are presented in Section 5 and Section 6 concludes.

\section{Literature Review}

There are three strands of literature to discuss in relation to this study: the literature on the economic behavior of religious organizations and churches, the empirical literature on estimating models of discrete games, and the literature on child care. We focus the remainder of this section on the first two of these literature areas. ${ }^{5}$

\footnotetext{
${ }^{5}$ The vast majority of the literature on child care examines the effects of child care availability on female labor supply decisions (see Kornstad and Thoresen, 2007, and Lefebvre and Merrigan, 2008, for recent examples). Others investigate the impact of child care on the children's outcomes (see Baydar and BrooksGunn, 1991, and Aughinbaugh, 2001). Another branch investigates cost and quality differences between
} 


\subsection{Literature on Religion \& Economics}

Most of the economic studies of religion focus on the behavior of individual church members. For example, McCullough et al. (2000) present a meta-analysis of studies that investigate whether religious people live longer than their non-religious counterparts. They find that religious involvement is associated with lower mortality rates. Gruber (2005) looks at the impact religiosity has on economic outcomes for church members and finds, for example, that religious participation is positively related to a higher level of income. Gruber and Hungerman (2008) look at the effect of repealing laws that prohibited retail activity on Sunday had on the behavior of individuals. They find that the likelihood of drinking and drug use increased in churchgoers following the repeal of these so-called "blue laws." Another branch of the religion literature has focused on external factors relating to church charitable giving. Gruber and Hungerman (2007) and Hungerman (2009) examine whether government expansion has crowded out of faith-based charity and find evidence of crowding-out particularly in homogenous communities.

Relative to the number of studies relating individuals' outcomes to their church attendance, very few economic studies focus on the behavior of the church itself or how such behavior is influenced by the actions of other churches. Two studies suggest a link between charitable giving and competition between churches. Zaleski and Zech (1995) investigate how competition between churches affects the amount of money members contribute to their

non-profit and for profit day care centers (see Mocan, 1997 and Gordon and Krashinsky, 2009). Blau and Mocan (2002) investigate the supply of quality for existing day care centers, but to our knowledge the decision to enter the day care market (i.e. supply day care centers) has not been investigated. None of these are particularly relevant to the study of church day care decisions. 
church. They find that Protestants give more when their congregation faces substantial competition whereas Catholics give more when their church represents a minority in a heavily concentrated market. Zaleski and Zech conjecture that this finding is likely due to each church improving their product due to competition but, they are unable to formally test this hypothesis. Pepall et al. (2006) look at church spending on charitable services (soup kitchens, etc.) and find that churches give more to these charitable services when faced with increased inter- and intra-denominational competition. They conclude that charitable service spending is one of the mechanisms by which churches compete.

Walrath (2008), to our knowledge, is the only other paper to use empirical discrete game techniques to examine church behavior. Walrath looks at the entry decisions of churches with the goal of determining whether there is "over entry" of Protestant churches in different geographic areas, due to the (relative) lack of a strong hierarchical structure (such as with the Catholic Church).

\subsection{Empirical Models of Discrete Games}

The empirical strategy used in this paper to model church behavior originates with Bresnahan and Reiss (1990) and Berry (1992). In Berry, a reduced-form profit function is used in a latent variable approach to identify the impact of demographic characteristics and the actions of rival firms on an airline's decision of which markets to enter. We extend this basic

framework by incorporating elements from Seim (2006) and Dai (2007). Seim, in examining the entry and location choices of video rental stores, allowed each agent's profit to depend not just on the entry decisions of others, but also on their chosen location. From a modeling 
standpoint, this was done by allowing the profit of agent $i$ (conditional upon entry) to depend on the number of other entrants within $x$ miles from agent $i$ 's location. In this manner, the estimated impact of a competitor two miles away, for example, may differ from the impact of a competitor eight miles away. As shown below, we will utilize a similar strategy.

In Dai's (2007) study on cell phone entry choices, the number of other competitors/entrants matters, but so too does their identity. In this context, Dai allows the profit of Cingular, for example, to be affected differently by Sprint or Verizon's entry into the market. Dai is able to estimate these firm-specific parameters because she observes each firm's entry decision in over 19,000 cities. We, on the other hand, observe only one equivalent "entry" decision per church, which makes following Dai's approach infeasible. In order to incorporate the basic premise behind Dai's modeling assumption, however, we allow the impact of competitor churches to differ depending on whether they belong to the same denomination or not. In this manner, we are able to incorporate information regarding spatial distances, as in Seim (2006), and allow for at least a small degree of heterogeneity in the effect of others' decisions.

\section{Data}

This study uses an original data set, collected over the summer of 2008, of Christian churches in Rutherford County, Tennessee and Williamson County, Tennessee. ${ }^{6}$ The two counties are part of the Nashville, Tennessee metropolitan statistical area (MSA) and have a combined population of over 400,000 residents inhabiting both urban and rural areas. We record the

\footnotetext{
${ }^{6}$ We collected information about all religious congregations in the two counties. We exclude some of these from the analysis due to the lack of realistic substitutes. We exclude a Jewish synagogue, a Buddhist temple, an Orthodox Church, Jehovah's Witnesses, and the Church of Jesus Christ of Latter Day Saints from the data.
} 
names, locations, denominations, membership sizes, day care service, and observable physical characteristics for a total of 424 churches: 135 in Williamson County and 289 in Rutherford County. The collection of church characteristics presents a difficult challenge as there is no comprehensive database of information on local churches. ${ }^{7}$ We obtained the listing of churches and information on each church's characteristics via internet searches, telephone calls, and finally physical visual inspections of each church in our sample. ${ }^{8}$

In order to determine the membership size of each church, we first contacted the local governing body of each denomination and then attempted to contact each church by telephone to confirm the membership size. ${ }^{9}$ We were successfully able to gather self-reported membership data for 256 (60 percent) of the churches. ${ }^{10}$ We used these reported membership figures, along with the other observed characteristics (described in greater detail below), to impute congregation sizes for the churches with missing values. We then used these figures for congregation sizes to categorize each church as being small (fewer than 75 families), medium (between 75 and 300 families), or large (more than 300 families). ${ }^{11}$

\footnotetext{
${ }^{7}$ Our attempts at obtaining information through government sources, such as tax filings and building permit requests yielded no usable data.

${ }^{8}$ We began using telephone book/yellow page listings. We supplemented this list using the listing of churches available through the HomeTownLocator ${ }^{\circledR}$ Gazetteer (http://www.hometownlocator.com), a website specializing in providing "local information" and through Google searches. We made physical inspection of all churches on our list, which lead us to encounter a number of churches that were not on our initial list.

${ }^{9}$ The local associations of Southern Baptist and United Methodist churches graciously provided us with access to the membership numbers for their churches. A local minister of a Church of Christ provided us with the membership sizes listed in Royster (2009).

${ }^{10}$ Most of the churches that we were unable to contact are very small congregations and are unlikely to offer services such as daycare. Approximately 70 percent of these were categorized in our visual inspections as having small church buildings. In addition, only 8 percent of the churches that provide child care programs had missing membership information.

${ }^{11}$ We transform membership numbers into three general size categories for three main reasons. First, because a child care program may attract new members to the church, there is a concern that membership size may be an endogenous characteristic. By transforming membership numbers into categories (meant to account for the number of families potentially utilizing child care, as well as the level of resources available to begin the child care program), we believe that this minimizes the potential endogeneity. Second, not all
} 
We were able to construct our child care measure using a variety of different sources. ${ }^{12}$ We consulted church websites and state child-care licensing lists, where applicable. We looked for signage indicating child care programs during our physical inspections and, when the results were inconclusive, we followed up with telephone inquiries to the church.

An important element in our model is the notion of same and different denominations. Denominations and affiliations are often part of a church's name, in other cases these were determined over the telephone. If a church did not claim to be affiliated with a denomination or if the denomination could not be determined, the church is classified as part of our "Other Christian" category. ${ }^{13}$

Remaining church characteristics were compiled from our visual inspections. While some of these measures, such as the presence of a playground or athletic field on church property, are objective, others are, admittedly, more subjective in nature. For example, we created a variable indicating whether the church appeared to have been built or remodeled in the past 10 years. We also categorized the physical size of the church building into one of three size categories. These detailed descriptions provide an accurate picture of the overall impression projected by each church to the community that is impossible to quantify with a single variable. We acknowledge the obvious downside of using subjective measures, but the lack

churches record membership in the same manner. Some record the total number of registered individuals, others count the number of registered families, and others record only the actual attendance. Since all three measures are transformed into a single count of families, we believe the broad categories also reduce measurement error to some extent. Finally, using general size categories minimizes any likely measurement error due to the imputation of some size values. Section 5.3 further discusses church size.

${ }^{12}$ We consider offering day care service to mean offering either full-time or part-time care during the normal business week. We do not count churches that only offer child care during church services or short term "Vacation Bible School" programs.

${ }^{13}$ This category includes all churches that cannot be categorized in our other denominations. We establish a unique category for a denomination if there are at least four churches in the denomination. Denominations which have fewer than four churches are categorized in this "other" category. 
of quantitative data on these churches forces us to improvise as best we can.

Summary statistics for the church data appear in Table 1 below.

TABLE 1A: Summary Statistics

\begin{tabular}{cccccccccc}
\hline & Total & Child Care & Website & $\begin{array}{c}\text { Av. Church } \\
\text { Size (\# fam.) }\end{array}$ & $\begin{array}{c}\text { Min Church } \\
\text { Size (\# fam.) }\end{array}$ & $\begin{array}{c}\text { Max Church } \\
\text { Size (\# fam.) }\end{array}$ & Small Size & Medium Size & Large Size \\
\cline { 2 - 10 } Southern Baptist & 104 & 22 & 59 & 214.9 & 6 & 2,652 & 40 & 50 & 14 \\
Church of Christ & 72 & 9 & 45 & 156.3 & 10 & 1,000 & 29 & 34 & 9 \\
Methodist & 46 & 10 & 26 & 208.7 & 8 & 2,674 & 28 & 10 & 8 \\
Missionary Baptist & 20 & 1 & 2 & 56.0 & 10 & 170 & 14 & 6 & 0 \\
Prim. Baptist & 16 & 0 & 1 & 59.9 & 14 & 106 & 11 & 5 & 0 \\
Presbyterian & 16 & 5 & 10 & 104.9 & 9 & 347 & 7 & 8 & 1 \\
Cumberland Presby & 12 & 1 & 5 & 85.1 & 33 & 152 & 5 & 7 & 0 \\
Church of God & 10 & 0 & 0 & 59.6 & 26 & 104 & 7 & 3 & 0 \\
Holy & 9 & 0 & 7 & 98.1 & 26 & 202 & 3 & 6 & 0 \\
Episcopal & 7 & 1 & 6 & 204.2 & 18 & 500 & 2 & 2 & 3 \\
Assemblies of God & 7 & 0 & 5 & 67.2 & 20 & 151 & 5 & 2 & 0 \\
Freewill Baptist & 6 & 0 & 3 & 76.0 & 40 & 142 & 4 & 2 & 0 \\
Catholic & 5 & 3 & 5 & $1,476.1$ & 250 & 2,183 & 0 & 1 & 4 \\
Lutheran & 5 & 0 & 5 & 126.6 & 22 & 240 & 2 & 3 & 0 \\
African Methodist & 4 & 0 & 1 & 64.3 & 24 & 82 & 2 & 2 & 0 \\
Other Christian & 78 & 7 & 55 & 189.6 & 12 & 3,000 & 40 & 30 & 8 \\
Other Pentecostal & 7 & 0 & 2 & 78.2 & 22 & 160 & 4 & 3 & 0 \\
\hline \hline Totals & 424 & 59 & 237 & 116 & -- & -- & 203 & 174 & 47 \\
\hline
\end{tabular}


TABLE 1B: Summary Statistics (cont'd.)

\begin{tabular}{cccccc}
\hline & New Building & $\begin{array}{c}\text { Buildable } \\
\text { Space }\end{array}$ & Playground & $\begin{array}{c}\text { Athletic } \\
\text { Fields }\end{array}$ & Gym \\
\cline { 2 - 6 } Southern Baptist & 37 & 79 & 59 & 18 & 21 \\
Church of Christ & 21 & 47 & 12 & 6 & 13 \\
Methodist & 10 & 38 & 25 & 4 & 9 \\
Missionary Baptist & 3 & 9 & 2 & 0 & 1 \\
Prim. Baptist & 1 & 5 & 1 & 0 & 1 \\
Presbyterian & 2 & 12 & 9 & 0 & 1 \\
Cumberland Presby & 4 & 7 & 6 & 3 & 0 \\
Church of God & 3 & 6 & 1 & 1 & 1 \\
Holy & 4 & 8 & 3 & 1 & 2 \\
Episcopal & 5 & 2 & 1 & 0 & 0 \\
Assemblies of God & 3 & 3 & 3 & 0 & 1 \\
Freewill Baptist & 3 & 4 & 3 & 0 & 0 \\
Catholic & 3 & 4 & 3 & 2 & 4 \\
Lutheran & 2 & 4 & 2 & 1 & 0 \\
African Methodist & 1 & 2 & 0 & 0 & 0 \\
Other Christian & 29 & 39 & 23 & 7 & 8 \\
Other Pentecostal & 2 & 5 & 1 & 1 & 1 \\
\hline \hline Totals & 133 & 274 & 154 & 44 & 63 \\
\hline \hline
\end{tabular}

As reported in Table 1A, almost one quarter of the churches in our sample are some form of Baptist, with Other Christian and Church of Christ being the second and third most common church types, respectively. Fifty-nine of the churches (14 percent) offer a child-care program and 83 percent of the churches with a program offer only part-time care. These programs are often marketed as part-time "Mother's Day Out" or "Preschool" programs. The majority of churches (58 percent) maintain their own website. The average congregation size is 116 families with Catholic churches having, by far, the largest number of members per church. The Baptist, Episcopal, and Methodist churches all average roughly 200 families, per church. The minimum number of families reported for a church in our sample is 6 and the maximum is $3,000 .{ }^{14}$ As mentioned above, these family membership size measures map

\footnotetext{
${ }^{14}$ For completeness we include all churches in the two counties. Churches that serve a small number of
} 
into the size categories on the right-hand side of Table $1 \mathrm{~A}$.

From Table 1B, we see that approximately 30 percent of the churches are either less than 10 years old or have been refurbished or remodeled in the past 10 years ("New building"). ${ }^{15}$ We also see that 65 percent of churches have enough undeveloped land to put an addition on their existing building ("Buildable space"), 36 percent of churches have a permanent, free-standing playground on their grounds, 10 percent have athletic fields, and 15 percent have a gymnasium. ${ }^{16}$

From the addresses we were able to determine the geographic coordinates for each church, which allows us to calculate the distances between churches and compile information about each church's geographic area. We gather median household income, poverty rates, population, and population density information from the 2000 Census. Because a church's decision may be influenced by the availability of full-time for-profit child care, we also record the locations and capacities of all for-profit day care centers in the two counties from the Tennessee Department of Human Services child care locator (http://www.ja.state.tn.us/accweb). ${ }^{17}$

families are unlikely to have the resources required to offer child care or other services. Their inclusion, if anything, would weaken our ability to observe strategic interactions.

${ }^{15}$ This seems to be a higher-than-anticipated percentage. This is probably due to the fact that the metropolitan Nashville area is one of the faster-growing areas of the country.

${ }^{16}$ We collected data on numerous other church features such as the presence of landscaping, church signs, bus or van service, stained glass, and paved parking lots among others. We suppress these from the tables for space considerations.

${ }^{17}$ All but one of the for-profit day care centers offers the option of full-time care and most offer only the full-time option. The list provided by the Department of Human Services only reports licensed day care centers. 
TABLE 2: Geographic Characteristics

\begin{tabular}{lccc}
\hline & Mean & Min & Max \\
\cline { 2 - 4 } $\begin{array}{l}\text { Distance to Closest Same-Denomination Church } \\
\text { (miles) }\end{array}$ & 2.56 & 0.07 & 12.00 \\
$\begin{array}{l}\text { Distance to Closest Different-Denomination } \\
\text { Church (miles) }\end{array}$ & 0.61 & 0.01 & 4.11 \\
$\begin{array}{l}\text { Four-Mile Radius Statistics: } \\
\text { Number of Same-Denomination Churches }\end{array}$ & 5.32 & 0 & 23 \\
$\quad$ Number of Different-Denomination Churches & 34.86 & 0 & 99 \\
$\quad$ Number of Church Child Care Centers & 5.81 & 0 & 17 \\
$\quad$ Number of For-Profit Day Care Centers & 10.62 & 0 & 28 \\
Capacity of For-Profit Day Care Centers & 944.92 & 0 & 2,731 \\
Income (\$1000s) & 51.86 & 20.54 & 117.67 \\
Population (1000s) & 7.35 & 1.39 & 16.12 \\
Population Density & 971.44 & 46.67 & $5,321.97$ \\
Poverty Rate & 0.09 & 0.00 & 0.33 \\
\hline
\end{tabular}

Summary statistics for geographic characteristics are found in Table 2. The mean distance to the nearest different-denomination church is 0.61 miles and the mean distance to a samedenomination church is 2.56 miles. The mean number of different-denomination churches located within a four mile radius of a church is 34.86 and the number of same denomination churches is 5.32. The mean number of for-profit day care centers within a 4 mile radius is 10.62 and these for-profit centers serve an average of 945 children. 


\section{Empirical Model}

\subsection{Model Setup}

Each church $i$ faces a decision of whether or not to offer service $s{ }^{18}$ We assume that churches make their decisions in order to maximize a value function. In following the common convention in the entry literature, we assume a reduced-form value function. The proper objective function for nonprofits is the subject of some prior research, including Harrison and Lybecker (2005). The reduced-from value function is appealing for studying church decisions because it allows us to be agnostic about what the value function actually is (profit or revenue maximization, membership size maximization, etc.). Our assumption does, however, require that all churches are optimizing the same objective function. ${ }^{19}$ We now consider the functional form of church $i$ 's value function.

Let $\Delta_{-i}$ denote set of churches of the same denomination as $i$, but excluding $i$, and let $\Omega_{i}$ denote the set of churches belonging to a different denomination. We can then write the value that church $i$ receives from offering service $s$ as:

$$
V_{i s}=X_{i} \beta+\sum_{b=1}^{3}\left[\gamma_{1 b} \sum_{j \in \Delta_{-i}} D_{j b}+\gamma_{2 b} \sum_{k \in \Omega_{i}} D_{k b}\right]+\omega_{i l}+\varepsilon_{i s}
$$

Several determinants of $i$ 's value are presented in equation (1). $X_{i}$ is a vector of observable characteristics for church $i$. This vector includes the observable church size and space

\footnotetext{
${ }^{18}$ The primary focus of this paper is on the provision of child care. However, we also estimate our model using data on the decision to have a website or not. Therefore, we will keep the notation general, rather than referring exclusively to the child care decision.

${ }^{19}$ A potential solution to this constraint would be to allow model parameters to vary across denominations. This would imply that Catholic churches, for example, may have one objective function, while Baptists have another. Unfortunately, allowing for such an approach is infeasible given our relatively small sample size.
} 
characteristics mentioned above, as well as demographic (Census) characteristics for the area surrounding $i$ 's location. To capture the impact that full-time day care centers may have on a church's decision we include in $X_{i}$ a variable measuring the total capacity of full-time for-profit day care centers within a four mile radius of each church. ${ }^{20}$ In equation $(1), D_{j b}$ indexes the decisions of churches of the same denomination as church $i$ located within distance band $b$ from church $i$ and $D_{k b}$ indexes the decisions of churches of different denominations located within distance band $b$ from church $i$. We include three different distance bands: (i) between 0 and 4 miles, (ii) between 4 miles and 8 miles, and (iii) between 8 miles and 16 miles. $^{21}$ By estimating separate $\gamma_{b}$ coefficients, we are able to distinguish between the impact of same- and different-denomination churches.

$\omega_{i l}$ is included to account for unobserved characteristics surrounding $i$ 's location. This unobservable term, whose construction is described in detail in the Appendix, is correlated for churches in close proximity to each other. $\varepsilon_{i s}$ represents $i$ 's idiosyncratic benefit from offering service $s .^{22}$ We assume that $\varepsilon$, which is observed by all churches, is distributed standard normal. For notational simplification, we refer to $\Theta\left(\Theta=\left\{\beta, \gamma_{1 b}, \gamma_{2 b}\right\}\right)$ as the set of parameters to be estimated.

\footnotetext{
${ }^{20}$ We treat full-time day care decisions as exogenous in our model because we do not believe that full-time day care is a close substitute to our church-run part-time programs. In contrast to full-time day care, which is typically open 50 to 60 hours per week, the majority of part-time child care programs operate two or three days a week for approximately five hours per day. There is also a substantial cost difference with day care centers in our sample charging approximately $\$ 160$ per week, whereas the church-run programs typically cost around $\$ 170$ per month.

${ }^{21}$ While the bands we have selected may appear to be quite "wide," the counties used in this research contain a proportion of rural areas. Anecdotally, it does not seem to be uncommon for individuals to attend a church six or more miles from their house. Our results are not sensitive to small changes in the band sizes.

${ }^{22}$ Efforts to incorporate greater heterogeneity into the model are encumbered by the reality that we observe each church only once in our data set.
} 


\subsection{Equilibrium}

We use a method of simulated moments (MSM) estimator, similar to that used by Dai (2007). We depart in several ways, however, due primarily to the fact that we observe decisions for only one "market". The key to any such estimation procedure is that we must be able to solve for the predicted equilibrium for observed and unobserved characteristics and parameter values. Our method of moments estimator, in the most general terms, searches for parameter values that make our predicted equilibrium as "close" as possible to the observed equilibrium.

The equilibrium condition in models of this variety is that, conditional upon the decisions of all other churches, church $i$ will only offer the service if the value of doing so is greater than zero. More formally, the equilibrium (binary) decision for church $i$ may be written:

$$
D_{i, s}=I\left\{V\left(D_{-i, s} \mid \Theta, \varepsilon\right) \geq 0\right\}
$$

where $I()$ is an indicator function taking the value of one if the value of the church's objective function is positive, given the (binary) strategies of the other churches $\left(D_{-i, s}\right)$. It is well-known that multiple-equilibria are probable in games of this type (see, for example, Hartmann, 2009). In order to select from among the various possible equilibria, we follow the suggestion of Bajari, Hong, and Ryan (2004), who find that the equilibrium that maximizes total joint profits is more likely to occur. We, therefore, select as the equilibrium that which maximizes total joint church value. With this selection rule, we are able to obtain a single equilibrium, which can be used in deriving the necessary moment conditions. There 
are alternative equilibrium selection techniques. For example, Berry (1992) assumes that airlines enter a given market in descending order of profitability. Ciliberto and Tamer (2009) propose a more general approach that does not require equilibrium selection assumptions. Their model, however, is better suited to samples where agent decisions are observed across a large number of markets, whereas we observe each church making a decision only once.

\subsection{Estimation}

In this section, we describe our MSM estimation strategy. Several technical details of the estimation appear in the Appendix. Our model contains two unobserved terms ( $\omega$ and $\varepsilon$ ). As the initial step of estimation, we take $R$ i.i.d. standard normal random draws of $\varepsilon$ for each of the $N$ churches. We also construct $R$ random draws of $\omega$. These draws are fixed throughout the estimation algorithm. Next, we specify a starting value for $\Theta$. Simple binary probit estimates are used for $\beta$ and the initial values of the $\gamma$ parameters are set to zero. For each of the sets of random draws, we then use equations (1) and (2), along with our selection rule, to find the predicted equilibrium. We proceed to do this for each of the $R$ random draws and then compute the relevant moment conditions (which are discussed in greater detail below). Defining $\widehat{\eta}$ as the column vector of residuals from our moment conditions, we repeat the above steps in order to minimize our objective function: $\widehat{\eta}^{\prime} W \widehat{\eta}$, where $W$ is a weighting matrix. As is commonly done in method of simulated moments estimation, we estimate the model in a two-stage procedure. In the first stage, we estimate the parameters $\widehat{\Theta}$ using an initial weighting matrix $W$. In our case, we assume that this initial weighting matrix is an identity matrix. We then use these initial estimates $(\widehat{\Theta})$ to construct an estimate 
of the optimal weighting matrix $\widehat{W}$, where $\widehat{W}=E\left[\widehat{\eta} \widehat{\eta}^{\prime}\right]^{-1}$. The model is then re-estimated using the estimated optimal weighting matrix. Reported coefficients reflect the parameter estimates from the second-stage estimation.

In our MSM estimation, we use the following moment conditions: (1) the difference between the predicted probability of offering a service and the observed decision for each church; (2) the difference between the predicted number of churches offering the service and the observed number of churches offering the service; (3) the difference between the predicted number of churches of a given denomination offering a service and the observed number of churches of a given denomination offering the service; (4) the difference between the predicted number of churches offering a service in each county and the observed number of churches offering the service in each county; and (5) the difference between the predicted number of churches offering a service in each Census tract and the observed number of churches offering the service in each Census tract.

\section{$5 \quad$ Results}

\subsection{Structural Estimates of Child Care}

The estimates of our structural model are presented in Table 3. 
TABLE 3: Structural Estimates of Child Care Choice

\begin{tabular}{|c|c|c|c|}
\hline & $\begin{array}{l}\text { Coefficient } \\
\text { (Std. Error) }\end{array}$ & & $\begin{array}{l}\text { Coefficient } \\
\text { (Std. Error) }\end{array}$ \\
\hline Same Denomination & & Small size & $-1.005 \star \star$ \\
\hline \multirow[t]{2}{*}{ Distance Band 1} & $0.302 * \star$ & & $(0.406)$ \\
\hline & $(0.149)$ & Large size & 1.884 *** \\
\hline \multirow[t]{2}{*}{ Distance Band 2} & 0.132 ** & & $(0.406)$ \\
\hline & $(0.064)$ & Mega size & 0.555 \\
\hline \multirow[t]{2}{*}{ Distance Band 3} & -0.034 & & $(0.635)$ \\
\hline & $(0.129)$ & New & $\begin{array}{l}0.733 \text { *** } \\
(0.285)\end{array}$ \\
\hline Different Denomination & & Buildable Lot & 0.707 * \\
\hline \multirow[t]{2}{*}{ Distance Band 1} & $-0.166 * \star$ & & $(0.440)$ \\
\hline & $(0.075)$ & Private Care Capacity & -0.005 \\
\hline \multirow[t]{2}{*}{ Distance Band 2} & -0.018 & & $(0.037)$ \\
\hline & $(0.054)$ & Poverty Rate & 3.581 \\
\hline \multirow[t]{7}{*}{ Distance Band 3} & 0.013 & & (3.861) \\
\hline & $(0.034)$ & Population (1000s) & 0.067 \\
\hline & & & $(0.043)$ \\
\hline & & Income (\$1000s) & 0.019 ** \\
\hline & & & $(0.008)$ \\
\hline & & Density & 3.18E-04 \\
\hline & & & $(0.000)$ \\
\hline
\end{tabular}

Three of the six $\gamma$ coefficients in the first data column are statistically significant at the 5 percent level. We generally find that $\gamma_{1 b}>0$ and $\gamma_{2 b}<0$, indicating that the decisions of same-denomination churches positively impact church $i$ 's value of providing child care, while the decisions of different-denomination churches negatively impact church $i$ 's value of providing child care. A plausible explanation for this finding is that different-denomination churches reduce the pool of potential children for a day care. On the other hand, in the spirit of competing for members, same-denomination churches may feel compelled to match services or amenities. Consistent with intuition, the impact of other churches diminishes with distance. We might speculate whether there appears to be cooperation between samedenomination churches in the child care decision. The positive $\gamma_{1 b}$ coefficient seems at odds with such a hypothesis, as might expect (a priori) a cooperative strategy to make a church 
less likely to offer child care if a nearby same-denomination church offers child care. This lack of coordination is consistent with Walrath's (2008) finding regarding the relative lack of hierarchical decision-making in Protestant churches.

As compared to medium-sized churches, small churches are less likely to provide child care and large churches are more likely to provide child care. Both estimates are statistically significant. This seems reasonable given that larger churches are likely to have both more families interested in child care and a resource advantage over smaller churches. Newer churches, with buildable space, and large lots, and churches in higher-income areas are also more likely to provide child care services. The positive coefficient on income may be capturing increased ability to pay for outside child care or it may reflect the presence of two-income families needing weekday child care. The other demographic variables are not statistically significant. Greater full-time capacity of non-church day cares has a negative (insignificant) impact on the value of providing child care, hinting of at least a small degree of substitutability between full-time and part-time care.

\subsection{Counterfactual Simulations}

\subsubsection{Simulating New Church Entry}

We examine the likely impact of increased competition by simulating the entry (i.e. creation) of a new church. Specifically, we assume that a new church is constructed next to the Williamson County Courthouse in downtown Franklin, Tennessee. We vary the size and the denomination of the new church in this exercise. The results for a small entrant appear in

Table 4 and the results for a medium-sized entrant appear in Table 5. While we include the 
entire population of churches in our simulation, to illustrate the results in a more tractable manner, Tables 4 and 5 show the results of these simulations only for a group of churches representative of our sample.

TABLE 4: Simulating the Impact of New Church (Small Size)

\begin{tabular}{|c|c|c|c|c|c|}
\hline & \multirow{3}{*}{$\begin{array}{l}\text { Baseline } \\
\text { Probability }\end{array}$} & \multicolumn{4}{|c|}{ Denomination of Entrant: } \\
\hline & & Baptist & Catholic & Methodist & Presby. \\
\hline & & Change & Change & Change & Change \\
\hline \multicolumn{6}{|l|}{ Downtown Franklin, TN } \\
\hline Cummins Street Church of Christ & 0.283 & 0.011 & 0.005 & 0.011 & 0.018 \\
\hline First Presbyterian Church & 0.973 & -0.013 & -0.013 & -0.013 & -0.013 \\
\hline First United Methodist Church & 0.897 & 0.021 & 0.004 & 0.018 & 0.018 \\
\hline Fourth Avenue Church of Christ & 0.743 & 0.014 & -0.019 & 0.004 & 0.014 \\
\hline Saint Pauls Episcopal Church & 0.723 & 0.060 & 0.011 & 0.053 & 0.083 \\
\hline Saint Philip Catholic Church & 0.847 & -0.008 & -0.001 & -0.005 & -0.011 \\
\hline \multicolumn{6}{|l|}{ Outside Franklin, TN } \\
\hline Burn's Tabernacle Baptist Church & 0.153 & -0.049 & 0.030 & -0.042 & -0.062 \\
\hline Christ Fellowship & 0.037 & 0.005 & 0.012 & -0.001 & -0.001 \\
\hline Clearview Baptist Church & 0.980 & -0.010 & -0.010 & -0.010 & -0.010 \\
\hline Cumberland Church & 0.020 & -0.021 & 0.006 & -0.017 & -0.024 \\
\hline First Baptist Church & 0.980 & -0.010 & -0.010 & -0.010 & -0.010 \\
\hline Franklin Church of Christ & 0.623 & 0.062 & -0.004 & 0.058 & 0.075 \\
\hline \multicolumn{6}{|l|}{ Neighboring Town } \\
\hline Brenthaven Presbyterian Church & 0.587 & 0.026 & -0.020 & 0.016 & 0.026 \\
\hline Brentwood Baptist Church & 0.970 & -0.010 & -0.007 & -0.010 & -0.010 \\
\hline Brentwood First Presbyterian Church & 0.890 & -0.002 & -0.018 & -0.002 & 0.005 \\
\hline Brentwood United Methodist Church & 0.967 & -0.013 & -0.023 & -0.016 & -0.013 \\
\hline Church of the Good Shepherd & 0.863 & -0.001 & -0.005 & -0.001 & 0.002 \\
\hline Concord Road Church of Christ & 0.737 & 0.007 & 0.000 & 0.010 & 0.024 \\
\hline Holy Family Catholic Church & 0.950 & -0.006 & -0.013 & -0.006 & 0.000 \\
\hline Otter Creek Church & 0.497 & -0.055 & 0.011 & -0.042 & -0.064 \\
\hline Probability New Church Offers Child Care & --- & 0.901 & 0.737 & 0.875 & 0.937 \\
\hline $\begin{array}{l}\text { Change in the Expected Number of Existing } \\
\text { Churches Providing Childcare }\end{array}$ & --- & 0.01 & -0.06 & -0.01 & 0.04 \\
\hline
\end{tabular}

Notes: For clarity, we have selected to present results for a small segment of the sample. a - The value presented is the expected number of child care programs for the above-listed churches (not the entire sample). 
TABLE 5: Simulating the Impact of New Church (Medium Size)

\begin{tabular}{|c|c|c|c|c|c|}
\hline & \multirow{3}{*}{$\begin{array}{l}\text { Baseline } \\
\text { Probability }\end{array}$} & \multicolumn{4}{|c|}{ Denomination of Entrant: } \\
\hline & & Baptist & Catholic & Methodist & Presby. \\
\hline & & Change & Change & Change & Change \\
\hline \multicolumn{6}{|l|}{ Downtown Franklin, TN } \\
\hline Cummins Street Church of Christ & 0.283 & 0.011 & 0.011 & 0.024 & 0.024 \\
\hline First Presbyterian Church & 0.973 & -0.013 & -0.013 & -0.013 & -0.013 \\
\hline First United Methodist Church & 0.897 & 0.021 & 0.018 & 0.018 & 0.021 \\
\hline Fourth Avenue Church of Christ & 0.743 & 0.014 & 0.004 & 0.020 & 0.020 \\
\hline Saint Pauls Episcopal Church & 0.723 & 0.060 & 0.053 & 0.086 & 0.089 \\
\hline Saint Philip Catholic Church & 0.847 & -0.008 & -0.005 & -0.011 & -0.014 \\
\hline Outside Franklin, TN & & & & & 0.000 \\
\hline Burn's Tabernacle Baptist Church & 0.153 & -0.049 & -0.042 & -0.069 & -0.075 \\
\hline Christ Fellowship & 0.037 & 0.005 & -0.001 & -0.001 & 0.002 \\
\hline Clearview Baptist Church & 0.980 & -0.010 & -0.010 & -0.010 & -0.010 \\
\hline Cumberland Church & 0.020 & -0.021 & -0.017 & -0.019 & -0.019 \\
\hline First Baptist Church & 0.980 & -0.010 & -0.010 & -0.010 & -0.010 \\
\hline Franklin Church of Christ & 0.623 & 0.062 & 0.058 & 0.091 & 0.101 \\
\hline Neighboring Town & & & & & 0.000 \\
\hline Brenthaven Presbyterian Church & 0.587 & 0.026 & 0.016 & 0.023 & 0.023 \\
\hline Brentwood Baptist Church & 0.970 & -0.010 & -0.010 & -0.010 & -0.010 \\
\hline Brentwood First Presbyterian Church & 0.890 & -0.002 & -0.002 & 0.005 & 0.001 \\
\hline Brentwood United Methodist Church & 0.967 & -0.013 & -0.016 & -0.013 & -0.013 \\
\hline Church of the Good Shepherd & 0.863 & -0.001 & -0.001 & 0.002 & 0.005 \\
\hline Concord Road Church of Christ & 0.737 & 0.007 & 0.010 & 0.024 & 0.024 \\
\hline Holy Family Catholic Church & 0.950 & -0.006 & -0.006 & 0.000 & 0.000 \\
\hline Otter Creek Church & 0.497 & -0.055 & -0.042 & -0.071 & -0.071 \\
\hline Probability New Church Offers Child Care & --- & 0.901 & 0.875 & 0.957 & 0.967 \\
\hline $\begin{array}{l}\text { Change in the Expected Number of Existing } \\
\text { Churches Providing Childcare }^{\mathrm{a}}\end{array}$ & --- & 0.01 & -0.01 & 0.07 & 0.07 \\
\hline
\end{tabular}

number of child care programs for the above-listed churches (not the entire sample).

There is a great deal of heterogeneity in the results and they reinforce the importance of formally modeling (or allowing for) strategic interaction. When a small Baptist or Presbyterian church enters, there is a net increase in the probability that existing churches provide child care services. For Catholic and Methodist entrants, the opposite reaction is predicted. A similar pattern emerges when looking at the impact of a new medium-sized church (Table 5). When the new medium-sized entrant is a Catholic church, there is a net decrease in the probability that existing churches provide child care services. The equilibrium effect of entry is ambiguous and depends on both the size and denomination of any potential entrant. 
Another interesting illustration in the counterfactual simulation is that even though the actions of different-denomination churches reduce church payoffs, the entry of a different denomination church may actually make church $i$ more likely to provide child care services, in equilibrium.

\subsubsection{The Effect of Demographic Changes}

To illustrate the impact that demographic changes have on church child care decisions, we consider a number of simulations where we assume 20 percent changes in household income and/or population. Once again, while all churches are used to simulate the predicted equilibrium, Table 6 shows the results of these simulations on a representative group.

TABLE 6: Effect of Demographic Changes on Probability of Offering Childcare Program

\begin{tabular}{|c|c|c|c|c|c|c|}
\hline & \multirow[b]{2}{*}{$\begin{array}{l}\text { Baseline } \\
\text { Probability }\end{array}$} & \multicolumn{5}{|c|}{ Event: } \\
\hline & & $\begin{array}{l}\text { Population } \\
\text { Increase } \\
\text { Change }\end{array}$ & $\begin{array}{l}\text { Income } \\
\text { Increase } \\
\text { Change }\end{array}$ & $\begin{array}{c}\text { Both } \\
\text { Increase } \\
\text { Change }\end{array}$ & $\begin{array}{c}\text { Both } \\
\text { Decrease } \\
\text { Change }\end{array}$ & $\begin{array}{c}\text { Day Care } \\
\text { Capacity Inc. } \\
\text { Change }\end{array}$ \\
\hline \multicolumn{7}{|l|}{ Downtown Franklin, TN } \\
\hline Cummins Street Church of Christ & 0.283 & -0.007 & -0.057 & -0.043 & -0.007 & -0.027 \\
\hline First Presbyterian Church & 0.973 & -0.010 & -0.010 & -0.010 & -0.017 & -0.010 \\
\hline First United Methodist Church & 0.897 & -0.003 & -0.020 & -0.007 & -0.017 & -0.030 \\
\hline Fourth Avenue Church of Christ & 0.743 & 0.003 & -0.063 & -0.063 & 0.047 & -0.017 \\
\hline Saint Pauls Episcopal Church & 0.723 & 0.017 & 0.017 & 0.053 & -0.087 & -0.040 \\
\hline Saint Philip Catholic Church & 0.847 & 0.007 & 0.000 & 0.010 & -0.047 & -0.017 \\
\hline \multicolumn{7}{|l|}{ Outside Franklin, TN } \\
\hline Burn's Tabernacle Baptist Church & 0.153 & 0.007 & -0.013 & -0.023 & -0.043 & -0.010 \\
\hline Christ Fellowship & 0.037 & 0.000 & 0.007 & 0.007 & 0.000 & -0.010 \\
\hline Clearview Baptist Church & 0.980 & -0.010 & -0.010 & -0.010 & -0.010 & -0.010 \\
\hline Cumberland Church & 0.020 & -0.007 & 0.003 & 0.010 & -0.010 & -0.010 \\
\hline First Baptist Church & 0.980 & -0.010 & -0.010 & -0.010 & -0.010 & -0.010 \\
\hline Franklin Church of Christ & 0.623 & 0.017 & 0.063 & 0.097 & -0.163 & -0.043 \\
\hline \multicolumn{7}{|l|}{ Neighboring Town (Brentwood, TN) } \\
\hline Brenthaven Presbyterian Church & 0.587 & -0.020 & 0.053 & 0.047 & -0.040 & -0.003 \\
\hline Brentwood Baptist Church & 0.970 & -0.010 & -0.007 & -0.007 & -0.007 & -0.010 \\
\hline Brentwood First Presbyterian Church & 0.890 & -0.010 & -0.010 & -0.013 & -0.057 & -0.017 \\
\hline Brentwood United Methodist Church & 0.967 & -0.010 & 0.000 & 0.000 & -0.033 & -0.013 \\
\hline Church of the Good Shepherd & 0.863 & 0.007 & 0.023 & 0.040 & -0.083 & -0.023 \\
\hline Concord Road Church of Christ & 0.737 & 0.033 & 0.073 & 0.087 & -0.200 & -0.043 \\
\hline Holy Family Catholic Church & 0.950 & -0.003 & -0.007 & -0.007 & -0.053 & -0.010 \\
\hline Otter Creek Church & 0.497 & -0.030 & 0.047 & 0.027 & 0.000 & 0.030 \\
\hline Expected Number of Child Care Programs ${ }^{a}$ & 13.72 & 13.68 & 13.80 & 13.90 & 12.88 & 13.40 \\
\hline
\end{tabular}


By using percentage changes (as opposed to uniform increases in the levels across all areas), some areas will experience larger increases or decreases than others. This has the interesting implication that some churches are less likely to provide child care services when population and incomes increase. Similarly, some churches are more likely to offer child care services when these demographic variables decrease. This is in direct contrast to the predictions from a simple binary probit or logit model where a positive coefficient in Table 3 would indicate that the probability of providing child care services necessarily increases with income/population increases. The implication being that failure to account for strategic interaction would result in "too many" churches providing child care as the population or income increases.

We also assume an exogenous 20 percent increase in full-time day care capacity. This increased capacity decreases the probability, for all but one church in Table 6, of offering child care services.

\subsection{Alternative Structural Specification}

In order to further examine the impact that size has on strategic interaction, we also estimate two models that slightly modify the model presented in equation (1). More specifically, we estimate a variation of (1) in which a church's payoff is impacted only by the choices of same-size churches. ${ }^{23}$ We also estimate a specification in which only larger churches impact a church's payoff. ${ }^{24}$ The estimates of $\gamma$ for these two alternative specifications appear in

\footnotetext{
${ }^{23}$ In this regard, we could redefine $\Omega_{-i}$ as the set of churches of the same size and denomination as $i$ (excluding $i$ ) and $\Delta_{i}$ as the set of churches of a different denomination (but same size) as $i$.

${ }^{24}$ Unfortunately, there is not sufficient variation in our data to simultaneously allow for rival church effects based on distance, denomination, and size.
} 
Table 7 .

TABLE 7: Alternative Structural Estimates of Child Care Choice

\begin{tabular}{|c|c|c|c|}
\hline \multicolumn{2}{|c|}{ Same-Size Churches Effect Profit } & \multicolumn{2}{|c|}{ Larger-Size Churches Effect Profit } \\
\hline & $\begin{array}{l}\text { Coefficient } \\
\text { (Std. Error) }\end{array}$ & & $\begin{array}{l}\text { Coefficient } \\
\text { (Std. Error) }\end{array}$ \\
\hline Same Denomination & & Same Denomination & \\
\hline Distance Band 1 & $\begin{array}{l}0.994 \text { ** } \\
(0.506)\end{array}$ & Distance Band 1 & $\begin{array}{c}0.324 \text { * } \\
(0.186)\end{array}$ \\
\hline Distance Band 2 & $\begin{array}{r}0.489 \\
(0.520)\end{array}$ & Distance Band 2 & $\begin{array}{r}0.161 \\
(0.236)\end{array}$ \\
\hline Distance Band 3 & $\begin{array}{l}-0.055 \\
(0.210)\end{array}$ & Distance Band 3 & $\begin{array}{l}-0.014 \\
(0.080)\end{array}$ \\
\hline Different Denomination & & Different Denomination & \\
\hline Distance Band 1 & $\begin{array}{l}-0.713 \text { ** } \\
(0.356)\end{array}$ & Distance Band 1 & $\begin{array}{l}-0.145 \\
(0.103)\end{array}$ \\
\hline Distance Band 2 & $\begin{array}{r}-0.078 \\
(0.258)\end{array}$ & Distance Band 2 & $\begin{array}{l}-0.047 \\
(0.079)\end{array}$ \\
\hline Distance Band 3 & $\begin{array}{r}0.014 \\
(0.038)\end{array}$ & Distance Band 3 & $\begin{array}{l}-0.006 \\
(0.015)\end{array}$ \\
\hline
\end{tabular}

The general pattern from Table 3 is robust to these modifications as the positive coefficients on same-denomination churches and negative coefficients on different-denomination churches remain. We see, however, that this effect is strongest for same-sized churches as the significance and magnitude of estimated coefficients are largest in the specification where the effect depends on whether the other church is of similar size. An explanation might be that churches view themselves as having "peers" and are influenced most by the decisions of their same-sized peers. This may indicate that, perhaps, child care services are used to appeal to potential church members. The need to "match" a child care decision is strongest when churches are otherwise similar. 


\subsection{The Decision to Maintain a Website}

In studying the decision of whether to provide child care or not, we found evidence of a statistically significant effect from the decisions of other churches. Given the expense and planning necessary to open a child care center, it may not be surprising that churches do not make the decision in isolation (i.e. $\gamma_{1}=\gamma_{2}=0$ ). A natural question, then, is whether this finding applies to other possible decisions. To address this question, we use our empirical model to analyze a church's decision regarding whether to maintain a congregation website or not. Child care programs and internet websites may both serve to benefit current church members as well as, possibly, attract new members. There is however, a sizable cost and effort difference between providing these two services and we expect the child care decision to be more strongly influenced by the decisions of others. The results from our estimation

are consistent with our prior expectations. The strategic interaction coefficients $(\gamma)$ for the website-choice model appear in Table 8. 


\begin{tabular}{cc}
$\begin{array}{c}\text { TABLE 8: Structural Estimates of } \\
\text { Website Choice }\end{array}$ \\
\hline & Coefficient \\
(Std. Error)
\end{tabular}

Notes: *** - significant at the $1 \%$ level

Only one of the six coefficients is statistically significant, that of same-denomination churches within the closest distance band. This estimate may be capturing a denominationwide coordination effort. For example, some hierarchical church organizations, such as the Episcopal Diocese of Tennessee, list the names and web addresses of member churches. It may be the case that, implicitly or explicitly, member churches are encouraged to maintain an internet presence. The results indicate, however, that the choices do not seem to be influenced by the choices of churches from different denominations. Given the low cost and effort necessary to maintain a website, the lack of interaction seems reasonable.

\section{Conclusions \& Extensions}

Churches provide many services to benefit their members and also to the community at large. They are also likely to face a different set of objectives than for-profit enterprises. The prevalence of church-sponsored activities along with the unique features underlying 
their decisions make the strategic behavior of churches an interesting point of study. In this paper, we have attempted to further our limited knowledge of the strategic behavior of churches.

We use a unique, hand-collected data set to formally model the decisions of churches in a discrete choice game structure. Then we test for the existence of strategic interactions between churches in the decision of whether to provide a service. Our results for the decision to provide a daytime child care program find evidence of statistically significant strategic interactions between churches. Interestingly, the data indicate that the impact of the interaction depends on whether the churches are from the same denomination. Specifically, a church is significantly more likely to offer child care service if a nearby same-denomination church offers child care. However, a church is significantly less likely to offer child care if a nearby different-denomination church offers it. A plausible explanation for these finding is that different-denomination churches reduce the pool of potential children for a day care perhaps because some families prefer all else equal to send their children to a day care run by their own denomination. Whereas, in the spirit of competing for members, churches may feel compelled to match services or amenities with same-denomination churches. The data also indicate that the impact of both same- and different-denomination churches diminishes with geographic distance. Each of these findings is robust to alternative specifications of the value function and to finer partitions of our data.

We then use these estimates to conduct a number of simulations, including a counterfactual simulation in which a new church enters the area. The results of the counterfactual indicate that there is ambiguity regarding the effect of increased "competition" (the presence 
of more churches). For example, when a medium-sized church enters the market, whether existing churches become more or less likely to offer child care services in response depends on the denomination of the entrant. There is no universal conclusion regarding the impact of increased competition. Such a result could not be found with standard probit or logit analysis.

This study is one of the first to explicitly model the choices and behaviors of churches. The results highlight the existence of strategic interactions between churches and demonstrate that a church's response to a rival's choice to offer a service depends crucially on whether the rival is of the same or of a different denomination. These findings suggest the presence of some unique considerations underlying church decisions and suggest that there are plenty of opportunities for further study on church behavior. A natural extension of this paper might be to consider the impact that churches have on private child care markets and vice versa.

\section{A Empirical Appendix}

\section{A.1 Constructing $\omega_{i l}$}

The term $\omega_{i l}$ captures characteristics of church $i$ 's location that we are unable to observe. This term should be positively correlated for nearby churches. To maintain consistency with our observed locational (Census) characteristics, we focus on Census tracts. For each Census tract, we draw $R$ random values from the standard normal distribution. Using a circle with a four mile radius placed over the geographic location of each church, we estimate the proportion of the circle that falls in each Census tract. For example, a four-mile radius circle drawn around Millview Church of Christ in Franklin, TN covers Census tracts 501, 502.1, 
and 510. Of the 50 square-mile area created by the circle, we estimate that approximately 80 percent falls in Census tract 501, 16 percent falls in tract 510, and 4 percent falls in Census tract 502.1. We use these percentages to construct a church-specific weighted average of the random draws from each Census tract. This weighted average is defined as $\omega_{i l}$.

Because the random draws are based on Census tract information, our approach has the implication that the random draws from churches covering the same Census tracts will be positively correlated. The degree of correlation depends on the relative coverages of the tracts.

\section{A.2 Estimation Algorithm Details}

Our model is a model of binary choice. As described in Section 4.2, our estimation strategy involves selecting an equilibrium from a game of strategic interaction. Given that all 424 churches in our sample make a binary decision, there are $2^{424}$ possible outcomes/equilibria to evaluate. Even with the most advanced computing power, evaluating all $2^{424}$ possible combinations (for each calculation of the objective function) is infeasible. In order to make our estimation more tractable, we restrict our search to outcomes in which the total number of churches providing child care falls between 45 and 75 . Using binary probit estimates as the starting values serves to ensure that our initial predicted probabilities are "reasonable." With the binary probit coefficients (and the strategic interaction parameters set to zero), the predicted equilibrium is for 52.6 churches providing child care. ${ }^{25}$ We monitor the iterations to verify that the limit cases (45 or 75$)$ are never chosen as the predicted equilibrium. The model converges for different starting values, as long as the initial predicted equilibrium is safely within our bounds.

\footnotetext{
${ }^{25}$ Recall from Table 1 that we observe 59 churches providing child care.
} 


\section{References}

[1] Aughinbaugh, Alison (2001): "Does Head Start Yield Long-Term Benefits?," Journal of Human Resources, 36, 641-665.

[2] Bajari, Patrick, Han Hong, and Stephen Ryan (2004): "Identification and Estimation of Discrete Games of Complete Information," NBER Working Paper No. T0301.

[3] Berry, Steven T. (1992): "Estimation of a Model of Entry in the Airline Industry," Econometrica, 60(4), 889-917.

[4] Blau, David M. and H. Naci Mocan (2002) "The Supply of Quality in Child Care Centers," The Review of Economics and Statistics, 84, 483-496.

[5] Baynar, Nazil and Jeanne Brooks-Gunn (1991): "Effects of Maternal Employment and Child-Care Arrangements on Preschoolers' Cognitive and Behavioral Outcomes: Evidence from the Children of the National Longitudinal Study of Youth," Developmental Psychology, 27, 932-945.

[6] Ciliberto, Frederico and Elie Tamer (2009): "Market Structure and Multiple Equilibria in Airline Markets," Econometrica (forthcoming).

[7] Dai, Mian (2007): "Strategic Interactions and Market Structure in the U.S. Mobile Telecommunications Industry," mimeo, Drexel University.

[8] Elzinga, Kenneth G. and Colin T. Page (2009): "Congregational Economies of Scale and the Megachurch: An Application of the Stigler Survivor Technique," mimeo, University of Virginia. 
[9] Gordon, Cleveland and Michael Krashinsky (2009): The Nonprofit Advantage: Producing Quality in Thick and Thin Child Care Markets," Journal of Policy Analysis and Management, 28, 440-462.

[10] Gruber, Jonathan (2005): "Religious Market Structure, Religious Participation, and Outcomes: Is Religion Good for You?," NBER Working Paper No. 11377.

[11] Gruber, Jonathan and Daniel M. Hungerman (2007): "Faith-Based Charity and Crowdout During the Great Depression," Journal of Public Economics, 91, 1043-1069.

[12] _____ and Daniel M. Hungerman (2008): "The Church vs. the Mall: What Happens When Religion Faces Increased Secular Competition?," Quarterly Journal of Economics, $123,831-862$.

[13] Harrison, Teresa D. and Kristina M. Lybecker (2005): "The Effect of the Nonprofit Motive on Hospital Competitive Behavior," Contributions to Economic Analysis \& Policy, 4(1), article 3. Available at: http://www.bepress.com/bejeap/contributions/vol4/iss1/art3.

[14] Hartmann, Wesley R. (2009): "Demand Estimation with Social Interactions and the Implications for Targeted Marketing," Marketing Science (conditionally accepted).

[15] Hungerman, Daniel M. (2009): "Crowd-out and Diversity," Journal of Public Economics, 93, 729-740.

[16] Iannaccone, Laurence R. (1998): "Introduction to the Economics of Religion," Journal of Economic Literature, 36(3), 1465-1495. 
[17] Kornstad, Tom and Thor Thoresen (2007): "A Discrete Choice Model for Labor Supply and Child care," Journal of Population Economics, 20, 781-803.

[18] Lefebvre, Pierre and Philip Merrigan (2008): "Child-Care Policy and the Labor Supply of Mothers with Young Children: A Natural Experiment from Canada," Journal of Labor Economics, 26, 519-548.

[19] Lindner, Eileen W., Mary C. Mattis, and June R. Rogers (1983): When Churches Mind the Children: A Study of Day Care in Local Parishes, National Council of Churches of Christ in the U.S.A., New York, NY.

[20] Mazzeo, Michael J. (2002): "Product Choice and Oligopoly Market Structure," RAND Journal of Economics, 33(2), 221-242.

[21] Mocan, H. Naci (1997): "Cost Functions, Efficiency, and Quality in Day Car Centers," The Journal of Human Resources, 32, 861-890.

[22] McCullough, Michael E., William T. Hoyt, David B. Larson, Harold G. Koenig, and Carl Thoresen (2000): "Religious Involvement and Mortality: A Meta-Analytic Review," Health Psychology, 19, 3, 211-222.

[23] Pepall, Lynne, Dan Richards, John Straub, and Michael DeBartolo (2006): "Crowding Out and Competition in the Religious Marketplace," mimeo, Tufts University.

[24] Royster, Carl H. (2009): Churches of Christ in the United States, 21st Century Christian Inc., Nashville, TN.

[25] Seim, Katja (2006): "An Empirical Model of Firm Entry with Endogenous ProductType Choices," RAND Journal of Economics, 37(3), 619-640. 
[26] Walrath, Michael W. (2008): "Religion as an Industry: Estimating a Strategic Entry Model for Churches," mimeo, University of St. Thomas.

[27] Zaleski, Peter A. and Charles E. Zech (1995): "The Effect of Religious Market Competition on Church Giving," Review of Social Economy, 53(3), 350-367. 